\title{
BMJ Open Triage in preventive child healthcare: a prospective cohort study of care use and referral rates for children at risk
}

\author{
Janine Bezem, ${ }^{1,2}$ Paul L Kocken, ${ }^{2,3}$ Mascha Kamphuis, ${ }^{4}$ Meinou H C Theunissen, ${ }^{2}$ \\ Simone E Buitendijk, ${ }^{5}$ Mattijs E Numans ${ }^{3}$
}

To cite: Bezem J, Kocken PL, Kamphuis $\mathrm{M}$, et al. Triage in preventive child healthcare: a prospective cohort study of care use and referral rates for children at risk. BMJ Open 2017;7:e016423. doi:10.1136/ bmjopen-2017-016423

- Prepublication history and additional material for this paper are available online. To view please visit the journal (http:// dx.doi.org/10.1136/bmjopen2017-016423).

Received 20 February 2017 Revised 6 September 2017 Accepted 27 September 2017

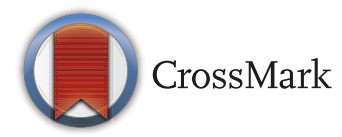

${ }^{1}$ Preventive Child Health Care Department, Gelderland-Midden Municipal Health Service, Arnhem, The Netherlands ${ }^{2}$ Department of Child Health, TNO, Leiden, The Netherlands ${ }^{3}$ Department of Public Health and Primary Care, Leiden University Medical Centre, Leiden, The Netherlands

${ }^{4}$ Zuid Holland West Municipal

Health Service, Zoetermeer, The Netherlands

${ }^{5}$ Imperial College London, Education Office, London, UK

Correspondence to

Janine Bezem;

janine.bezem@vggm.nl

\section{ABSTRACT}

Objectives A novel triage approach to routine assessments was introduced to improve the efficiency of Preventive Child Healthcare (PCH): $\mathrm{PCH}$ assistants carried out pre-assessments of all children and sent the children with suspected health problems to follow-up assessments conducted by a physician or nurse. This two-step approach differed from the usual approach, in which physicians or nurses assessed all children. This study was aimed to examine the impact of triage and task shifting on care for children at risk identified by PCH or parents and schools. Design and participants An observational prospective cohort design was used, with an analysis of the basic registration data from the preventive health assessments for 1897 children aged 5 to 6 , and 10 to 11 , years from a sample of 41 schools stratified by socioeconomic status, region of $\mathrm{PCH}$ service and urbanisation.

Setting A comparison was made between two $\mathrm{PCH}$ services in the Netherlands that used the triage approach and two PCH services that provided the usual approach. Main outcome measures The primary outcome measures were the referral rates to either additional PCH assessments or external services. The secondary outcome measures were the rates of $\mathrm{PCH}$ assessments requested by, for example, parents and schools.

Results Overall, a higher referral rate to additional $\mathrm{PCH}$ assessments was found for the triage approach than for the usual approach (OR $1.3,95 \% \mathrm{Cl} 1.0$ to 1.6$)$, mainly in the age group of 5 to 6 years (OR 1.9, 95\% $\mathrm{Cl} 1.3$ to 2.7). We found a lower rate of referral to external services in the triage approach $(\mathrm{OR} 0.4,95 \% \mathrm{Cl} 0.3$ to 0.7$)$ and a higher referral rate to $\mathrm{PCH}$ assessments on request $(\mathrm{OR}=4.6$, $95 \% \mathrm{Cl} 3.0$ to 7.0 ).

Conclusions The triage approach provides extra opportunities to deliver PCH assessments and PCH assessments on request for children at risk. Further research is needed into the cost benefits of the triage approach.

\section{BACKGROUND}

Changes in the prevalence of disorders such as mental health problems, the need to prevent violence, increases in lifestyle-related problems and apparent health inequities between subgroups of children all mean that improvements are needed in the system of community preventive services for

\section{Strengths and limitations of this study}

- The inclusion of four Preventive Child Healthcare (PCH) services from urban and rural areas, improving the external validity of the study.

- The inclusion of a random sample of schools stratified by socioeconomic status, region of $\mathrm{PCH}$ service and urbanisation.

- We selected groups of children that were homogeneous in terms of gender and age, and controlled in the analyses for differences in socioeconomic status.

- We were not able to monitor the outcome of the referrals to additional $\mathrm{PCH}$ assessments or to external services because we were not allowed to analyse the individual details of the children in the absence of informed consent.

children. ${ }^{1-6}$ These preventive services face several challenges, such as accessibility to care, programme quality and the efficient use of professionals. ${ }^{78}$ Changes and improvements to healthcare systems could be accomplished by introducing triage and the shifting of tasks between healthcare professionals. Task shifting is defined as the delegation of existing tasks to current or new professionals who have less and/or more specific training. ${ }^{9}$ Triage and task shifting may result in the more optimal use of the skills and expertise of healthcare professionals, reduce workloads for physicians and nurses, and therefore improve the quality of care and result in greater patient satisfaction. ${ }^{910}$ Research in primary care shows that shifting tasks from physicians to nurses dealing with chronic disorders results in more additional assessments by nurses after the initial visit of the patient and that the number of referrals to secondary care is similar for nurses and physicians. Nevertheless, this type of task shifting has a clearly positive impact on patient satisfaction. $^{11-14}$

Preventive Child Healthcare (PCH) services in several countries provide vaccinations and 


\begin{tabular}{|l|l|}
\hline Routine assessment: & $\begin{array}{l}\text { A health assessment routinely conducted by PCH services accessible for } \\
\text { all Dutch children and provided unsolicited and free of charge, using a } \\
\text { pre-defined schedule of invitations to the assessments from birth till the } \\
\text { age of 18. }\end{array}$ \\
\hline $\begin{array}{l}\text { Usual approach of } \\
\text { routine assessments: }\end{array}$ & $\begin{array}{l}\text { The "traditional" way of routine assessments provided to all children by a } \\
\text { PCH physician and PCH assistant, or by a PCH nurse who is sometimes } \\
\text { supported by a PCH assistant. }\end{array}$ \\
\hline $\begin{array}{l}\text { Triage approach of } \\
\text { routine assessments: }\end{array}$ & $\begin{array}{l}\text { A two-step assessment approach of routine assessments, in which all } \\
\text { children are preselected by a PCH assistant for a follow-up assessment. } \\
\text { In case of suspected health problems the routine assessment also } \\
\text { includes a follow-up assessment by a PCH physician or nurse. }\end{array}$ \\
\hline Pre-assessment: & $\begin{array}{l}\text { First step in the triage approach conducted by a PCH assistant } \\
\text { accessible for all children to select children with suspected health } \\
\text { problems. }\end{array}$ \\
\hline Follow-up assessment: & $\begin{array}{l}\text { Second-step in the triage approach by a PCH physician or nurse to } \\
\text { children with suspected health problems who are referred after a pre- } \\
\text { assessment by the PCH assistant. }\end{array}$ \\
\hline $\begin{array}{l}\text { Assessment on } \\
\text { request: }\end{array}$ & $\begin{array}{l}\text { Assessment at the request of parties such as parents or school } \\
\text { professionals who suspect risk factors with regard to the health of the } \\
\text { child. These assessments are conducted by a PCH physician or nurse } \\
\text { and are not part of the routine assessment schedule. In both usual and } \\
\text { triage approach, assessments on request are possible. }\end{array}$ \\
\hline $\begin{array}{l}\text { Additional PCH } \\
\text { assessment: }\end{array}$ & $\begin{array}{l}\text { An additional assessment of a child identified with health problems, } \\
\text { conducted by a PCH physician or nurse, resulting from a routine } \\
\text { assessment or an assessment on request. }\end{array}$ \\
\hline External service: & $\begin{array}{l}\text { A general practitioner, specialist or other care provider, to which children } \\
\text { identified with health problems have been referred as a result of a } \\
\text { routine assessment. additional PCH assessment, or assessment on } \\
\text { request by PCH. }\end{array}$ \\
\hline Extra care: & $\begin{array}{l}\text { An additional PCH assessment or care by an external service directed to } \\
\text { children identified with health problems. }\end{array}$ \\
\hline
\end{tabular}

Figure 1 Glossary of the assessment stages and care provided by the usual and triage approaches in Preventive Child Healthcare $(\mathrm{PCH})$.

routine assessments using a predefined age schedule (see figure 1 for a glossary of terms used for PCH care). The aim is to monitor child growth and development and to prevent child health problems. ${ }^{815}$ In the Dutch PCH programmes, all children receive 17 unsolicited routine assessments: 13 in the first 3 years of life (in well-child clinics) and 4 in the age group 4 to 18 years (in school health services).

The routine assessments consist of standardised screening procedures targeting several health-related topics. Specially trained community-based physicians, nurses and assistants ('PCH professionals') work separately from specialised clinical care providers such as paediatricians or other clinical health professionals. In the usual approach in $\mathrm{PCH}$, all children are initially assessed by a PCH physician or nurse, who will sometimes receive support from $\mathrm{PCH}$ assistants who have been trained at the secondary vocational level that focuses specifically on medical issues. The Dutch PCH services are free of charge and attendance rates can be more than $85 \% .{ }^{16}{ }^{17}$ When problems are identified, PCH physicians and nurses decide whether there is any need for advice, additional assessments by $\mathrm{PCH}$ or referral to external services such as a general practitioner or a specialist. The referral to the services appropriate to the needs of the children is an essential component of the health screening programmes delivered by $\mathrm{PCH}{ }^{18}$

The $\mathrm{PCH}$ programme needs to be more flexible and demand driven than in the current predefined schedule, in which there are only four assessments during a school career, in order to respond to the changing care needs of the children. PCH assessments traditionally provide snapshots of the dynamic process of development and growth of children at isolated points in time, even though most children will have no problems at those times. PCH needs to improve its accessibility, be more available for children and parents throughout the school period, and offer care when it is needed.

To achieve a more flexible provision of care, a two-step triage approach was developed for children aged 4 to 18 years involving triage and the shifting of tasks from PCH physicians and nurses to $\mathrm{PCH}$ assistants. ${ }^{19}$ In the triage approach, children are pre-assessed by a $\mathrm{PCH}$ assistant using a strict protocol which includes the completion of questionnaires by parents and teachers, and face-to-face screening (that covers areas such as growth, hearing and vision). Only children with suspected health concerns are selected by the PCH assistant for follow-up assessment by a PCH physician or nurse. The triage approach could reduce the involvement of physicians and nurses in routine assessments, and therefore release resources that can be used for PCH assessments for children at risk. When children are referred for follow-up assessment, the nature and complexity of the suspected health problems determines whether that assessment should be conducted by a physician or a nurse: physicians attend to medical and developmental disorders and nurses attend mostly to psychosocial problems and lifestyle issues. Pre-assessments at schools by PCH assistants are conducted in the absence of parents but with parental consent. Follow-up assessments by a physician or nurse take place in the presence of a parent in order to allow for interaction with the PCH professional about the potential health concerns detected by the $\mathrm{PCH}$ assistant. In both the usual and the triage approaches, children in whom health concerns have been identified in the routine assessments may be referred to extra care, in other words additional PCH assessments or external services appropriate to the children's specific needs. In both approaches, children may be assessed at the request of, for example, parents or school professionals (we will refer to these assessments as 'PCH assessments on request'). PCH assessments on request are intended for children from age groups other than those predefined for the routine assessments in order to reach all children in need of care. A pilot study of the triage approach that compared appointment attendance and referral rates in the triage and the usual approach was conducted before this study. We found that attendance levels were the same, and that the referral rate to additional PCH assessments or external services was lower, in the triage approach than in the usual approach. ${ }^{19}$ Another study showed that routine assessments in a triage approach detect health concerns as effectively as the usual approach. ${ }^{20}$ Our study of the costs of the routine assessments in the two approaches showed that the triage approach resulted in a cost reduction of about one-third for the age group of 5 to 6 years and a minimal cost reduction for the age group of 10 to 11 years. ${ }^{21}$ This study examined the impact of triage and task shifting on care for children at risk who were identified by PCH or by external parties such as parents and schools. It addresses the following research questions: 
- What are the rates of referral to additional PCH assessments and external services resulting from routine assessments in the triage approach as compared with the usual PCH approach?

- What are the rates of PCH assessments on request, including the referral rates resulting from these assessments, when a triage approach is used rather than the usual approach?

\section{METHODS}

An observational prospective cohort design was used to study the research questions.

\section{Study sample}

The study was conducted with routine and administrative data from four PCH services active in four separate regions in the Netherlands. Two services used the triage approach and two services the usual approach. Each PCH service covers a population of around 125000 children from birth to the age of 18 years. A sample of primary schools stratified for socioeconomic status (low, middle and high status), region of the PCH service and urban or rural area was randomly selected from these four services. To obtain sufficient and equal numbers of children for both study groups (in other words, the triage and usual approach), 20 schools that used the triage approach were matched with 21 schools that used the usual approach. The socioeconomic status of the schools was determined using national census statistics. Routine assessments were conducted by PCH services in Dutch primary schools for two age groups: 5 to 6 years and 10 to 11 years. To study the referral rates to additional PCH assessments and external services, the study included all the children aged 5 to 6 and 10 to 11 years from the selected schools who were offered a routine assessment. A sample of 1008 children who received the triage approach was compared with a sample of 986 children who received the usual approach. In the usual approach, all children aged 5 to 6 years are assessed by a physician and children aged 10 to 11 years are assessed by a nurse. When medical problems are suspected, nurses must refer the child for an additional $\mathrm{PCH}$ assessment by a physician. In the triage approach, all children are pre-assessed by a PCH assistant and follow-up assessments are conducted by PCH physicians and nurses. In addition to routine PCH assessments, we also investigated $\mathrm{PCH}$ assessments on request. To study the referral rates to $\mathrm{PCH}$ assessments on request, we followed all children attending the schools selected for this study for a maximum of 12 months (the reference population). This resulted in a sample of 4050 children in the schools where the triage approach was used and 4611 children in the schools where the usual approach was adopted. Since there were no vital changes or interventions in healthcare, and all the data were fully anonymised and coded, and since the data did not include medical details that could be linked to individuals before inclusion in this study on a population level, no informed consent was needed.

\section{Data collection}

Study data were registered in digital PCH records during the study period. In addition, data were registered for the $\mathrm{PCH}$ assessments on request. The assessment procedures were described in uniform protocols for all $\mathrm{PCH}$ services covered by this study and the participating PCH professionals were informed about these protocols. For the sake of completeness, we compared a random sample from the analysis data file with the data in the PCH records. Children in the study sample who received triage pre-assessments or assessments as usual were included from January to April 2012. Data relating to children requiring triage follow-up assessment and $\mathrm{PCH}$ assessments on request were included and the children were followed until December 2012.

\section{Procedures}

When weight problems, visual disorders and/or psychosocial problems were identified by $\mathrm{PCH}$ physicians and nurses, the children were referred to additional PCH assessments or external services. We chose these three health indicators because the relevant procedures are established and known to be valid. ${ }^{172}$

Children were referred for these indications after the follow-up assessment in the triage approach, and after the routine assessment in the usual approach. When school professionals or parents suspected the presence of risk factors in children, they were allowed to request an assessment by PCH for further identification. After problems were identified by a PCH physician or nurse, these children could also be referred for additional PCH assessments or to external services (figure 2).

PCH professionals registered and coded sociodemographic variables in digital $\mathrm{PCH}$ records that included gender and age, weight, visual and psychosocial health status, and referrals to additional $\mathrm{PCH}$ assessments and to external services. The socioeconomic status of the children was established using national census statistics and on the basis of postal codes for their home addresses using education, income and employment status of the local population. ${ }^{23}$

Weight, visual and psychosocial health status were assessed and recorded in the digital PCH records as usual. Problems with weight (both overweight and underweight) were determined using the body mass index (BMI) and assessment by the professional. The thresholds used by the international obesity task force were adopted as the BMI cut-off points for overweight and obesity. ${ }^{24} \mathrm{SD}$ scores for BMI were based on the Dutch general population. ${ }^{25}$ Visual disorders, including amblyopia and impaired vision, were determined using a visual acuity test: the Snellen chart with SD scores based on the Dutch general population. ${ }^{22}$ Psychosocial problems included child behaviour and emotional problems, social interaction problems and child abuse. The identification of these psychosocial problems was based on the assessment made by the PCH professional, and it also included the child's scores on the Strengths and Difficulties Questionnaire. ${ }^{26} 27$ 


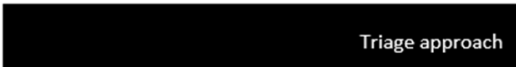

Triage approach

Routine assessment by PCH
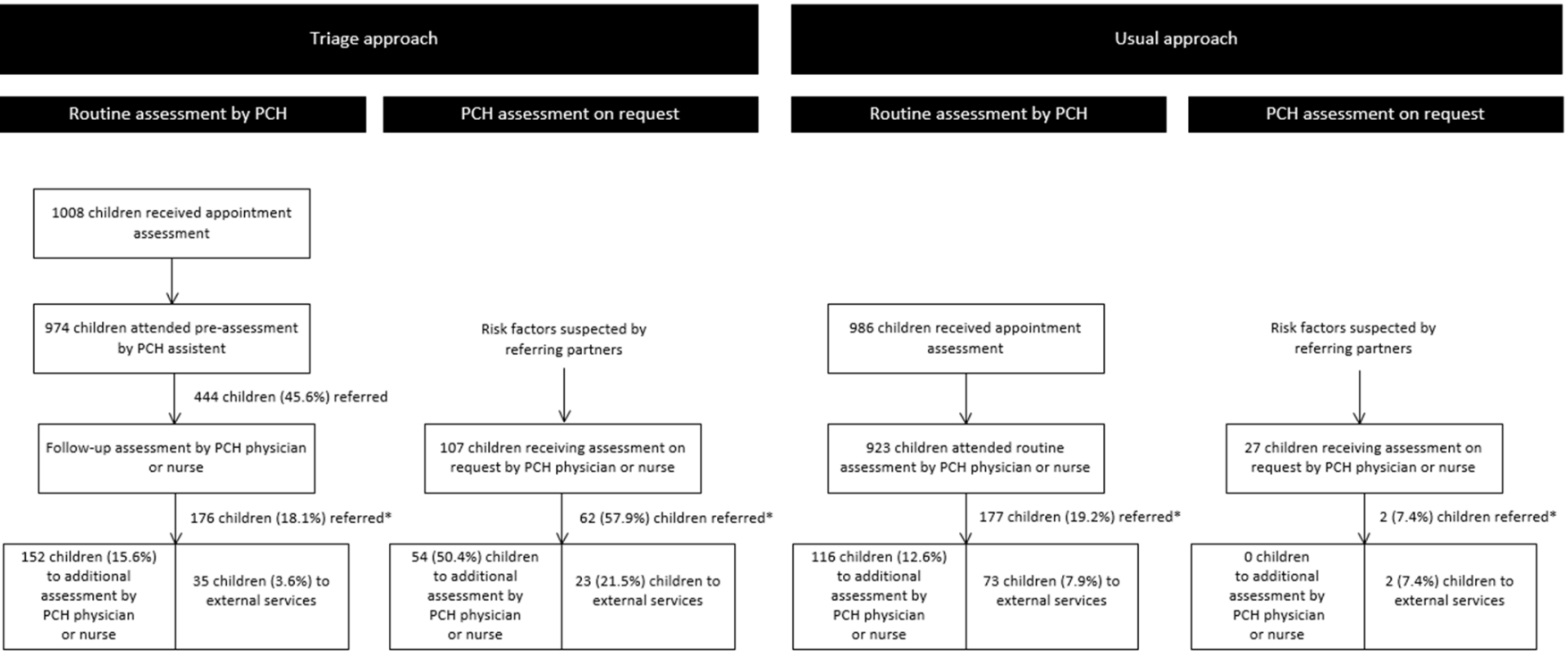

Figure 2 Flowchart for the PCH routine assessment and assessment on request in the triage and usual approaches. *Some children were referred to both additional $\mathrm{PCH}$ assessment and external services. $\mathrm{PCH}$, Preventive Child Healthcare.

All referrals to additional $\mathrm{PCH}$ assessments or to external services were registered and coded by the $\mathrm{PCH}$ professionals.

Finally, records were kept of whether requests for $\mathrm{PCH}$ assessments were made by parents, school professionals or professionals in well-child care. The referrals to additional PCH assessments and to external services subsequent to these assessments were also registered.

\section{Study outcomes}

The primary outcomes of this study were the rates of referral to additional $\mathrm{PCH}$ assessment and to external services as a result of the routine assessments. The secondary outcomes were the rates of PCH assessments on request, and rates of referral to additional $\mathrm{PCH}$ assessment and to external services resulting from these assessments.

\section{Statistical analyses}

Our first step was to look at differences in background characteristics such as gender, age and socioeconomic status between the two cohorts using $\chi^{2}$ tests. Second, we studied the rates of referral to follow-up assessments in the triage approach. We also made separate analyses of the referral rates to additional PCH assessment and external services, and the sum of referrals to additional $\mathrm{PCH}$ assessments and to external services. We tested differences in rates of referral between the two approaches using three separate logistic regression analyses with the outcome variables 'referral to additional PCH assessment', 'referral to external services' and 'sum of referrals to additional PCH assessments and external services'. Adjusted ORs were calculated in all logistic regression analyses. We adjusted for socioeconomic status. Missing data were excluded from the regression analyses. These analyses were repeated for the subgroups of children referred for weight problems, visual disorders and psychosocial problems.

Because routine $\mathrm{PCH}$ assessments were conducted in the age groups of 5 to 6 and 10 to 11 years, the interaction effects of child age and the type of approach (in other words, the triage and usual approaches) on the outcome measures were studied. When we found interaction effects associated with child age, the analyses were repeated separately for the age groups of 5 to 6 and 10 to 11 years.

Third, we compared the rates of PCH assessments on request in the two approaches using Fisher's exact test. In these analyses, the total sample of children of the schools participating in this study was used as the reference population. We also assessed whether children were referred by different parties (school, parents, wellchild care, other) in the two approaches. Furthermore, we assessed the differences between the two approaches in the rates of referral for the group of children who received a $\mathrm{PCH}$ assessment on request. Due to the small number of children referred to PCH assessment on request in the usual approach, it was not possible to adjust for background characteristics. We therefore used $\chi^{2}$ and Fisher's exact tests (categories were tested separately). In these analyses, the sample of the group of children who received a $\mathrm{PCH}$ assessment on request was used as the reference population.

Effects were considered to be statistically significant when the $\mathrm{p}$ value was $\leq 0.05$ (two sided). SPSS Statistics was used to analyse the data (SPSS V.22.0 for Windows, SPSS).

\section{RESULTS}

\section{Study sample}

To study the rates of referral to additional PCH assessments and external services, we compared a sample of 
Table 1 Characteristics of children assessed using the triage and usual approaches to Preventive Child Healthcare

\begin{tabular}{|c|c|c|c|}
\hline Characteristics & $\begin{array}{l}\text { Triage } \\
\text { approach } \\
\mathrm{n}(\%)\end{array}$ & $\begin{array}{l}\text { Usual } \\
\text { approach } \\
\text { n (\%) }\end{array}$ & p Value \\
\hline $\begin{array}{l}\text { Children receiving routine } \\
\text { assessment }{ }^{\star}\end{array}$ & $\mathrm{n}=974$ & $n=923$ & \\
\hline \multicolumn{4}{|l|}{ Gender } \\
\hline Boy & 485 (49.8) & 455 (49.3) & 0.83 \\
\hline Girl & $489(50.2)$ & $468(50.7)$ & \\
\hline \multicolumn{4}{|l|}{ Age (years) } \\
\hline$\leq 8$ & $480(49.3)$ & $468(51.8)$ & 0.28 \\
\hline$\geq 9$ & $494(50.7)$ & $436(48.2)$ & \\
\hline \multicolumn{4}{|l|}{ Socioeconomic status } \\
\hline Low & 415 (42.9) & $342(37.1)$ & $<0.01$ \\
\hline Middle & $304(31.4)$ & $372(40.4)$ & \\
\hline High & $249(25.7)$ & 207 (22.5) & \\
\hline $\begin{array}{l}\text { Children receiving routine } \\
\text { assessment on request } †\end{array}$ & $n=107$ & $n=27$ & \\
\hline \multicolumn{4}{|l|}{ Gender } \\
\hline Boy & $67(62.6)$ & $10(40.0)$ & 0.04 \\
\hline Girl & $40(37.4)$ & $15(60.0)$ & \\
\hline \multicolumn{4}{|l|}{ Age (years) } \\
\hline$\leq 8$ & 78 (72.9) & $21(77.8)$ & 0.61 \\
\hline$\geq 9$ & $29(27.1)$ & $6(22.2)$ & \\
\hline \multicolumn{4}{|l|}{ Socioeconomic status } \\
\hline Low & $68(65.4)$ & $17(70.8)$ & 0.61 \\
\hline Middle & $22(21.2)$ & $2(8.3)$ & \\
\hline High & $14(13.5)$ & $5(20.8)$ & \\
\hline
\end{tabular}

*Missing data (triage approach: socioeconomic status $n=6$; usual approach: age $n=19$, socioeconomic status $n=2$ ). †Missing data (triage approach: socioeconomic status $n=3$; usual approach: gender $n=2$, socioeconomic status $n=3$ ).

1008 children who were eligible for a pre-assessment in the triage approach with a sample of 986 children who were eligible for an assessment in the usual approach (figure 2). To investigate the rates of $\mathrm{PCH}$ assessments on request, a sample of 4050 children in the schools where the triage approach was used was compared with a sample of 4611 children in the schools where the usual approach was adopted.

We found no differences in the ages or genders of the children receiving routine assessments in the triage and usual approaches. However, the socioeconomic status of the children did differ: the triage sample included more children with a lower socioeconomic status (table 1). No differences were found in the ages or socioeconomic status of the group of children receiving $\mathrm{PCH}$ assessments on request. There was a gender difference in the group of children receiving assessments on request: more boys received an assessment on request in the triage approach than in the usual approach (table 1).

Referral to additional PCH assessments or to external services The percentage of children referred from pre-assessment to a follow-up assessment in the first step of the triage approach was $45.6 \%$ (444 of 974).

We did not find any difference between the rates of referral for the total group of children referred to extra care (in other words, the children referred to additional $\mathrm{PCH}$ assessments and/or to external services) in the two approaches: 176 of 974 children $(18.1 \%)$ in the triage group were referred to extra care after the follow-up assessments, and 177 of 923 children (19.2\%) were referred from the usual approach $(\mathrm{OR}=0.9,95 \%$ C.I. $(0.7$ to 1.1)) (figure 2, table 2). A closer look at these rates indicates that there was a higher referral rate to additional PCH assessments (OR 1.3, 95\% CI 1.0 to 1.6) and a lower referral rate to external services in the triage approach than in the usual approach (OR $0.4,95 \%$ CI 0.3 to 0.7 ).

\section{Weight problems}

The percentage of children referred to extra care was different in the group of children found to have a weight problem. In the triage group, 44 of 974 children (4.5\%) were referred to extra care for a weight problem after 150 of $974(15.4 \%)$ had been referred to a follow-up assessment by a PCH physician or nurse. In the usual group, 48 of 923 children (5.2\%) were referred to extra care. The lower referral rate by triage $\mathrm{PCH}$ for a weight problem was particularly striking in the referrals to external services: 3 of 974 children $(0.3 \%)$, as opposed to 13 of $923(1.4 \%)$ in the usual PCH group (OR=0.2, $95 \%$ CI 0.1 to 0.7$)$.

\section{Psychosocial problems}

We found no difference between the triage and usual groups in the percentage of children with psychosocial problems who were referred to extra care. However, we found a difference in the percentage of referrals to external services: $1.2 \%$ of children (12 of 974) in the triage group were referred to external services; the rate of referral was $2.5 \%$ (23 of 923) in the usual group $(\mathrm{OR}=0.5$, $95 \%$ CI 0.2 to 1.0 ).

\section{Visual problems}

No differences were found between the referral rates to extra care in the triage and usual approaches for the health indicator 'visual disorder'.

Interaction effects were found for child age. In the age group of 5 to 6 years, no differences were found between the two approaches in the total referral rates for extra care (including additional PCH assessments and external services). When looking closer at the type of extra care to which children were referred, we found a higher referral rate to additional $\mathrm{PCH}$ assessments in the age group of 5 to 6 years when the triage approach was used $(\mathrm{OR}=1.9$, $95 \%$ CI 1.3 to 2.7 ).

In the age group of 10 to 11 years, a lower referral rate was found to extra care in the triage group (including 
Table 2 Association between referral to additional PCH assessment or to external services and the $\mathrm{PCH}$ approach (triage vs usual care)

\begin{tabular}{|c|c|c|c|c|c|c|}
\hline & \multicolumn{2}{|l|}{$\begin{array}{l}\text { Triage approach } \\
\mathrm{n}=974\end{array}$} & \multirow{3}{*}{$\begin{array}{l}\begin{array}{l}\text { Usual } \\
\text { approach } \\
\mathrm{n}=923\end{array} \\
\\
\text { Referral after } \\
\text { assessment by } \\
\text { PCH physician } \\
\text { or nurse } \\
\mathrm{n}(\%) \\
\end{array}$} & \multirow[b]{3}{*}{ OR $^{*}$} & \multirow[b]{3}{*}{$95 \% \mathrm{Cl}$} & \multirow[b]{3}{*}{ p Value } \\
\hline & $\begin{array}{l}\text { Referral } \\
\text { after pre- } \\
\text { assessment by } \\
\text { PCH assistant }\end{array}$ & $\begin{array}{l}\text { Referral after } \\
\text { receiving a follow- } \\
\text { up assessment from } \\
\text { a PCH physician or } \\
\text { nurse }\end{array}$ & & & & \\
\hline & n (\%) & n (\%) & & & & \\
\hline \multicolumn{7}{|l|}{ All referrals } \\
\hline $\begin{array}{l}\text { Children referred to follow-up } \\
\text { assessment }\end{array}$ & $444(45.6)$ & - & - & - & - & \\
\hline $\begin{array}{l}\text { Children referred to additional } \\
\text { PCH assessment and/or external } \\
\text { services }\end{array}$ & - & $176(18.1) \dagger$ & 177 (19.2) & 0.9 & 0.7 to 1.1 & 0.42 \\
\hline Additional PCH assessment & - & $152(15.6)$ & $116(12.6)$ & 1.3 & 1.0 to 1.6 & 0.09 \\
\hline External services & - & $35(3.6)$ & $73(7.9)$ & 0.4 & 0.3 to 0.7 & $<0.01$ \\
\hline \multicolumn{7}{|c|}{ Indication for referral: weight problem } \\
\hline $\begin{array}{l}\text { Children referred to follow-up } \\
\text { assessment }\end{array}$ & $150(15.4)$ & - & - & - & - & \\
\hline $\begin{array}{l}\text { Children referred to additional } \\
\text { PCH assessment and/or external } \\
\text { services }\end{array}$ & - & $44(4.5)$ & $48(5.2)$ & 0.8 & 0.5 to 1.3 & 0.36 \\
\hline Additional PCH assessment & - & $43(4.4)$ & $38(4.1)$ & 1.0 & 0.7 to 1.6 & 0.89 \\
\hline External services & - & $3(0.3)$ & $13(1.4)$ & 0.2 & 0.1 to 0.7 & 0.01 \\
\hline \multicolumn{7}{|c|}{ Indication for referral: visual disorder } \\
\hline $\begin{array}{l}\text { Children referred to follow-up } \\
\text { assessment }\end{array}$ & $47(4.8)$ & - & - & - & - & \\
\hline $\begin{array}{l}\text { Children referred to additional } \\
\text { PCH assessment and/or external } \\
\text { services }\end{array}$ & - & $16(1.6)$ & $22(2.4)$ & 0.7 & 0.3 to 1.3 & 0.25 \\
\hline Additional PCH assessment & - & $10(1.0)$ & $10(1.1)$ & 1.0 & 0.4 to 2.4 & 0.94 \\
\hline External services & - & $8(0.8)$ & $14(1.5)$ & 0.5 & 0.2 to 1.3 & 0.15 \\
\hline \multicolumn{7}{|c|}{ Indication for referral: psychosocial problem } \\
\hline $\begin{array}{l}\text { Children referred to follow-up } \\
\text { assessment }\end{array}$ & $152(15.6)$ & - & - & - & - & \\
\hline $\begin{array}{l}\text { Children referred to additional } \\
\text { PCH assessment and/or external } \\
\text { services }\end{array}$ & - & $48(4.9)$ & $57(6.2)$ & 0.8 & 0.5 to 1.1 & 0.17 \\
\hline Additional PCH assessment & - & $38(3.9)$ & $36(3.9)$ & 0.9 & 0.6 to 1.5 & 0.82 \\
\hline External services & - & $12(1.2)$ & $23(2.5)$ & 0.5 & 0.2 to 1.0 & 0.05 \\
\hline
\end{tabular}

*Logistic regression analyses with referral by $\mathrm{PCH}$ as the outcome variable, the approach (triage follow-up assessment or usual assessment) as the independent variable and socioeconomic status as covariate.

†Some children were referred to both additional PCH assessment and external services.

$\mathrm{PCH}$, Preventive Child Healthcare.

additional $\mathrm{PCH}$ assessments and external services) than in the usual group (OR=0.6, 95\% CI 0.4 to 0.9 ). This effect was found for additional PCH assessments in particular $(\mathrm{OR}=0.5,95 \%$ CI 0.3 to 1.0$)$.

In the age group of 10 to 11 years, a lower referral rate was found to extra care for weight problems $(\mathrm{OR}=0.6,95 \% \mathrm{CI}$
0.3 to 1.0$)$ and for psychosocial problems (OR=0.5, 95\% CI 0.3 to 0.8 ) when the triage approach was used. When looking closer at the type of extra care, we found a higher referral rate to additional $\mathrm{PCH}$ assessments for psychosocial problems in the age group of 5 to 6 years when the triage approach was used (OR=2.2, 95\% CI 1.0 to 4.5$)$. 
Table 3 Association between $\mathrm{PCH}$ approach (triage vs usual care) and children receiving $\mathrm{PCH}$ assessments on request and referral of these children to additional $\mathrm{PCH}$ assessments or to external services

\begin{tabular}{|c|c|c|c|}
\hline & $\begin{array}{l}\text { Triage } \\
\text { approach }\end{array}$ & $\begin{array}{l}\text { Usual } \\
\text { approach }\end{array}$ & \\
\hline & n (\%) & n (\%) & p Value \\
\hline & $\mathrm{n}=4050^{*}$ & $n=4611^{*}$ & \\
\hline \multirow{2}{*}{$\begin{array}{l}\text { Children receiving } \mathrm{PCH} \\
\text { assessment on request }\end{array}$} & 107 (2.6) & $27(0.6)$ & $<0.01$ \\
\hline & $n=107$ & $n=27$ & \\
\hline \multicolumn{4}{|l|}{ Referring parties $†$} \\
\hline School & $18(16.8)$ & $0(0.0)$ & 0.02 \\
\hline Parents & $18(16.8)$ & $5(18.5)$ & 0.78 \\
\hline Well-child care & $33(30.8)$ & $0(0.0)$ & 0.01 \\
\hline Other & $1(0.9)$ & $1(3.7)$ & 0.36 \\
\hline Unknown & $37(34.6)$ & $21(77.8)$ & $<0.01$ \\
\hline $\begin{array}{l}\text { Referral to additional } \\
\text { PCH assessment and/or } \\
\text { external services }\end{array}$ & $62(57.9)$ & $2(7.4)$ & $<0.01$ \\
\hline $\begin{array}{l}\text { Additional PCH } \\
\text { assessment }\end{array}$ & $54(50.5)$ & $0(0.0)$ & $<0.01$ \\
\hline External services & $23(21.5)$ & $2(7.4)$ & 0.09 \\
\hline
\end{tabular}

${ }^{*}$ All children (4-12 years) at the schools included.

†The five categories were tested separately. For example, the school as the referring party was tested relative to all categories as a reference to analyse differences between the triage and usual approaches.

$\mathrm{X}^{2}$ test/Fisher's exact test.

$\mathrm{PCH}$, Preventive Child Healthcare.

\section{$\mathrm{PCH}$ assessments on request}

We found a higher rate of $\mathrm{PCH}$ assessments on request in the triage approach than in the usual approach $(\mathrm{p}<0.01)$ (table 3). In particular, a higher rate was found for PCH assessments at the request of school professionals and of well-child care for the triage approach than in the usual approach. Furthermore, we found differences between the two approaches for the referral rates to additional $\mathrm{PCH}$ assessments pursuant to the $\mathrm{PCH}$ assessments on request. Half of the children seen on request were referred to additional $\mathrm{PCH}$ assessments and one out of five to external services in the triage approach. No children in the usual approach were referred to additional $\mathrm{PCH}$ assessments and 2 of 27 children $(7.4 \%)$ were referred to external services.

\section{DISCUSSION}

This study examined the impact of triage and task shifting on care for children at risk identified by $\mathrm{PCH}$ or by external parties such as parents and schools. We compared the rates of referral to additional $\mathrm{PCH}$ assessments and external services after the identification of health concerns pursuant to routine assessments with either the triage approach or the usual approach. We did not find any differences between the total sum of referral rates to additional PCH assessments and external services in the two approaches. However, the referral rate to additional $\mathrm{PCH}$ assessments was higher in children aged 5 to 6 years and lower in children aged 10 to 11 years in the triage approach. Overall, the referral rates to external services resulting from the routine assessments were lower when triage was used rather than the usual approach. The differences between the referral rates could be attributed to the different processes used to identify health problems in the two approaches. In the two-step triage approach, children requiring follow-up (in other words, children with suspected health problems) are assessed twice. After the pre-assessment by the PCH assistant, the PCH physician or nurse and the parents need to focus only on the suspected health problems. In this follow-up assessment, more time may be available to provide advice, recommendations and reassurance. This could possibly reduce the need for referral to external services. Because the routine assessments in the usual approach are intended to cover all the different screening items, little time is available for a further investigation of the problems identified. This could explain why the referral rate to external services is higher in the usual approach than in the triage approach. In particular, the lower referral rates in the triage approach to external services for weight problems and psychosocial problems as indicators of health problems could be explained by the positive fact that more time is available to investigate the problems during the follow-up assessment. Children with visual problems are usually referred directly to external services in both approaches and this could explain the equal referral rates to external services for these problems. The lower referral rate to external services in the triage approach may also be explained by the fact that problems-minor psychosocial problems, for example-are resolved in the period between the pre-assessment and the follow-up assessment. On the other hand, parents may seek care in the period between the pre-assessment and the follow-up assessment and this may reduce the referral rates to external services in the triage approach.

In addition, the discipline conducting the assessment may also explain the differences found between the two approaches. The aim of task shifting and pre-assessment by PCH assistants is to save time in order to allow for additional $\mathrm{PCH}$ assessments by physicians and nurses so that more attention can be paid to the care needs of children at risk. And indeed, we found a higher referral rate to additional $\mathrm{PCH}$ assessments for the age group of 5 to 6 years when the triage approach was used. However, in the age group of 10 to 11 years, we found a lower referral rate to additional $\mathrm{PCH}$ assessments in the triage approach. This could possibly be explained by the fact that all children aged 10 to 11 years are assessed by a nurse in the usual approach and children aged 5 to 6 years are assessed by a physician. When medical problems are suspected, nurses must refer the child for an additional PCH assessment by a physician. This leads to 
extra referrals to additional PCH assessments. However, in the triage approach, the $\mathrm{PCH}$ assistant preselects the children with suspected medical problems and refers them immediately for a follow-up assessment by a PCH physician. This is routine in the triage approach and does not qualify as an additional PCH assessment. Furthermore, it is also possible that there are more additional assessments with $\mathrm{PCH}$ nurses than with $\mathrm{PCH}$ physicians and that this leads to a higher referral rate to additional $\mathrm{PCH}$ assessments for the age group of 10 to 11 years in the usual approach.

A pilot study with the triage approach showed that referral rates to additional $\mathrm{PCH}$ assessments or to external services were lower than in the usual approach. ${ }^{19}$ This has been confirmed in our study looking at referral to external services. Our results relating to referral rates to additional PCH assessments associated with the shifting of tasks from $\mathrm{PCH}$ physicians and nurses to $\mathrm{PCH}$ assistants for the age group of 10 to 11 years are in line with studies of task shifting in primary care, which found more additional assessments when nurses took over tasks from physicians, even though the number of referrals did not change. $^{1213}$

We examined the results of the PCH assessments on request. The triage approach was developed to reduce the cost of routine assessments and release resources to conduct PCH assessments on request for children with specific healthcare needs. Higher rates were found for $\mathrm{PCH}$ assessments on request in the triage approach. The referrals for these children came from school professionals in particular. Differences in PCH assessments on request between the triage and usual approach may be attributed to the fact that the triage approach results in a greater awareness among school professionals of the abilities of physicians and nurses to assess children on request. This explanation is in line with the findings of our earlier study of school professionals, who responded that $\mathrm{PCH}$ services with the triage approach contribute more to support for children with specific needs than the usual approach. ${ }^{28}$ However, we did not study the reasons for referral to $\mathrm{PCH}$ assessments on request. A possible reason for the introduction of the triage approach could be to improve the cost-benefit ratio for $\mathrm{PCH}$. An earlier study of the costs of the routine assessments showed that the triage approach resulted in a cost reduction. However, we did not study the costs of onward referrals and of the PCH assessments on request.

Finally, the outcomes of the triage approach in $\mathrm{PCH}$ as measured in this study may have been affected by its relatively recent introduction by comparison with the usual approach. It can reasonably be expected that the triage approach will have a stronger impact on the number of PCH assessments on request when this approach has been in place for a longer period of time. It takes time to establish a relationship with parties such as school professionals.

\section{Strengths and limitations of the study}

The strengths of this study are that it is a 'real-life' observational comparison that included four $\mathrm{PCH}$ regional services and random samples of schools stratified by socioeconomic status and urbanity. We were able to use data from a homogeneous group of children with regard to gender and age range, and we controlled for differences in socioeconomic status. The sample in the current study was selected from the general Dutch population from urban and rural areas, making generalisation of the findings to other $\mathrm{PCH}$ organisations possible. Although the power conditions to study the referral rates on request were not met in the analyses, the differences between the approaches were large enough to find significant associations. All four PCH services in this study used the same guidelines and registration procedures, reducing the possibility of identification and reporting bias. A limitation is that we were not allowed to use and analyse the individual details of the children referred to additional $\mathrm{PCH}$ assessments or to external services given the absence of informed consent.

\section{Implications for practice}

Economic circumstances and changing health demands require the development of new ways of delivering care. More efficiency and flexibility in the delivery of the PCH programme are needed to address challenges such as reduced budgets, workforce shortages, the growing need for optimal use of expertise of professionals and the wish to provide customised care. Other PCH services in the Netherlands have introduced more flexible PCH care delivery, with task shifting. ${ }^{29}$ The aim of the triage approach is to deliver more customised care in response to health issues that arise in the life cycle of children. The triage approach has the potential to deliver a basic package of care for all children while preserving the strengths of the preventive health service: a low threshold and the wide reach necessary for the early identification of health problems. In earlier studies, we found that access to $\mathrm{PCH}$ and the detection of health problems were comparable with the usual approach. In this study, we found that physicians and nurses working with a triage approach delivered extra $\mathrm{PCH}$ care in terms of additional PCH assessments for the age group of 5 to 6 years and a higher rate of $\mathrm{PCH}$ assessments at the request of parents, school professionals or professionals in wellchild care targeting children with specific needs. Our study provides further insight into the possibilities of a more flexible and demand-driven delivery of preventive health services for children.

\section{Future research}

Further research is needed to assess the satisfaction of the children, young people and their parents with a triage approach to routine $\mathrm{PCH}$ assessment and the resulting care. Research is also needed to determine the actual quality of detection and referrals using a triage approach. This would allow us to determine the accuracy of referral to extra care (in other words, to determine whether a referral is justified or not) and to enhance our 
understanding of the equity of care distribution to the children needing healthcare. Further research is needed into the outcomes of referral to extra care. Moreover, we studied only the costs of the routine assessments, but research will also be needed into the costs of onward referrals to extra care and the costs of $\mathrm{PCH}$ assessments on request. So further research is needed to determine whether the triage approach is actually cost-effective. Moreover, research is required to determine the impact of the triage approach on the long-term need for care.

\section{Conclusions}

The triage approach provides extra opportunities to deliver PCH assessments and $\mathrm{PCH}$ assessments on request for children at risk. In the triage approach, fewer children are referred to external services than in the usual approach in the case of the routine assessments. More research is needed into the outcomes of referral to extra care and into the cost benefits of the triage approach.

Acknowledgements We thank the personnel of the PCH services Municipal Health Service Noord- en Oost- Gelderland, Municipal Health Service Hollands Noorden, Municipal Health Service Drenthe and Municipal Health Service Gelderland-Midden for participating in this study and D. Heinen MSc for statistical advice.

Contributors JB had the original idea, contributed to the development of the triage protocols, acquisition and interpretation of data and drafting of this article. MN contributed to the revision of the drafts and the intellectual content of this article. SB contributed to the revision of the drafts and the intellectual content of this article. MK contributed to the data collection, and to the analysis and interpretation of the data. She was involved in revising the article. MT contributed to the conception and design, analysis and interpretation of data. She was involved in revising the article. PK contributed to the conception and design, analysis and interpretation of data and drafting of the article. He supervised the execution of the study. Finally, all authors read and approved the final article.

Funding This study was financially supported by grants 156511002 and 156520007 from ZonMw-the Netherlands Organization for Health Research and Development. The funding source had no role in the study design, data collection, data interpretation, data analysis or writing of the report.

\section{Competing interests None declared.}

Patient consent Detail has been removed from this case description/these case descriptions to ensure anonymity. The editors and reviewers have seen the detailed information available and are satisfied that the information backs up the case the authors are making.

Ethics approval The Medical Ethics Committee of Leiden University Medical Centre (reference P11.161/NV/nv).

Provenance and peer review Not commissioned; externally peer reviewed.

Data sharing statement Anonymised data can be provided by TNO to researchers on request.

Open Access This is an Open Access article distributed in accordance with the Creative Commons Attribution Non Commercial (CC BY-NC 4.0) license, which permits others to distribute, remix, adapt, build upon this work non-commercially, and license their derivative works on different terms, provided the original work is properly cited and the use is non-commercial. See: http://creativecommons.org/ licenses/by-nc/4.0/

(c) Article author(s) (or their employer(s) unless otherwise stated in the text of the article) 2017. All rights reserved. No commercial use is permitted unless otherwise expressly granted.

\section{REFERENCES}

1. Chung PJ, Lee TC, Morrison JL, et al. Preventive care for children in the United States: quality and barriers. Annu Rev Public Health 2006;27:491-515.
2. Coker TR, Thomas T, Chung PJ. Does well-child care have a future in pediatrics? Pediatrics 2013;131(Suppl 2):S149-59.

3. Wolfe I, Thompson M, Gill P, et al. Health services for children in western Europe. Lancet 2013;381:1224-34.

4. Baltag V, Pachyna A, Hall J. Global overview of school health services: data from 102 countries. Health Behav Policy Rev 2015;2:268-83.

5. Kuo AA, Inkelas M, Lotstein DS, et al. Rethinking well-child care in the United States: an international comparison. Pediatrics 2006;118:1692-702.

6. Macinko J, Starfield B, Shi L. The contribution of primary care systems to health outcomes within Organization for Economic Cooperation and Development (OECD) countries, 1970-1998. Health Serv Res 2003;38:831-65.

7. Koplan JP, Fleming DW. Current and future public health challenges. JAMA 2000;284:1696-8.

8. World Health Organization. Pairing children with health services. Copenhagen: WHO Regional Office for Europe, 2010.

9. Fulton BD, Scheffler RM, Sparkes SP, et al. Health workforce skill mix and task shifting in low income countries: a review of recent evidence. Hum Resour Health 2011;9:1

10. Buchan J, Dal Poz MR. Skill mix in the health care workforce: reviewing the evidence. Bull World Health Organ 2002;80:575-80

11. Martínez-González NA, Djalali S, Tandjung R, et al. Substitution of physicians by nurses in primary care: a systematic review and metaanalysis. BMC Health Serv Res 2014;14:214.

12. Martínez-González NA, Rosemann T, Djalali S, et al. Task-shifting from physicians to nurses in primary care and its impact on resource utilization: a systematic review and meta-analysis of randomized controlled trials. Med Care Res Rev 2015;72:395-418.

13. Horrocks S, Anderson E, Salisbury C. Systematic review of whether nurse practitioners working in primary care can provide equivalent care to doctors. BMJ 2002;324:819-23.

14. Venning P, Durie A, Roland M, et al. Randomised controlled trial comparing cost effectiveness of general practitioners and nurse practitioners in primary care. BMJ 2000;320:1048-53.

15. Wieske RC, Nijnuis MG, Carmiggelt BC, et al. Preventive youth health care in 11 European countries: an exploratory analysis. Int $\mathrm{J}$ Public Health 2012;57:637-41.

16. Brugman E, Reijneveld SA, Verhulst FC, et al. Identification and management of psychosocial problems by preventive child health care. Arch Pediatr Adolesc Med 2001;155:462-9.

17. Theunissen MH, Vogels AG, Reijneveld SA. Early detection of psychosocial problems in children aged 5 to 6 years by preventive child healthcare: has it improved? J Pediatr 2012;160:500-4.

18. Wood R, Stirling A, Nolan C, et al. Trends in the coverage of 'universal' child health reviews: observational study using routinely available data. BMJ Open 2012;2:e000759.

19. Bezem J. Theunissen M, Buitendijk SE, Kocken PL. A novel triage approach of child preventive health assessment: an observational study of routine registry-data. BMC Health Serv Res 2014;14:498.

20. Bezem J, Theunissen M, Kamphuis M, et al. A novel triage approach to identifying health concerns. Pediatrics 2016;137:e2015081420.

21. Bezem J, van der Ploeg $C$, Numans $M$, et al. Preventive child health care at elementary school age: The costs of routine assessments with a triage approach. PLoS One 2017;12:e0176569.

22. Groenewoud JH, Tjiam AM, Lantau VK, et al. Rotterdam AMblyopia screening effectiveness study: detection and causes of amblyopia in a large birth cohort. Invest Ophthalmol Vis Sci 2010;51:3476-84.

23. Knol F. Statusontwikkeling van wijken in Nederland 1998-2010 [Status development of neighbourhoods in the Netherlands 1998-2010]. The Netherland: The Haque: The Netherlands Institute for Social Research, 2012.

24. Cole TJ, Bellizzi MC, Flegal KM, et al. Establishing a standard definition for child overweight and obesity worldwide: international survey. BMJ 2000;320:1240-3.

25. Fredriks $\mathrm{AM}$, van Buuren $\mathrm{S}$, Wit JM, et al. Body index measurements in 1996-7 compared with 1980. Arch Dis Child 2000;82:107-12.

26. Goodman R. The strengths and difficulties questionnaire: a research note. J Child Psychol Psychiatry 1997:38:581-6.

27. Vogels AG, Crone MR, Hoekstra F, et al. Comparing three short questionnaires to detect psychosocial dysfunction among primary school children: a randomized method. BMC Public Health 2009;9:489

28. Bezem J, Heinen D, Reis R, et al. Improving access to school health services as perceived by school professionals. Submitted.

29. Benjamins SJ, Damen ML, van Stel HF. Feasibility and impact of doctor-nurse task delegation in preventive child health care in the Netherlands, a controlled before-after study. PLoS One 2015; 10:e0139187. 